\title{
GÊNERO, SEXUALIDADE E NAÇÃO: A RAINHA GINGA ENTRE O ESQUECIMENTO E A INVENÇÃO DO MUNDO
}

\author{
Mariana Alves da Silva ${ }^{1}$ \\ Helder Thiago Maia $^{2}$
}

\begin{abstract}
Resumo: Neste trabalho, analisamos a construção da personagem Rainha Ginga, nos dois romances mais recentes de José Eduardo Agualusa em que essa figura histórica aparece, Teoria Geral do Esquecimento (2012) e A rainha Ginga: e de como os africanos inventaram o mundo (2014), buscando compreender como a versão literária da Rainha Ginga permite refletir sobre memória e passado e, ainda, sobre identidade nacional em suas articulações com gênero e sexualidade. Nossa análise, baseada nos estudos de Inocência Mata $(2006,2014)$, Mario César Lugarinho (2016) e Helder Thiago Maia (2018), busca encontrar propostas de leitura queer da construção de Ginga como personagem.
\end{abstract}

Palavras-Chave: Rainha Ginga. José Eduardo Agualusa. Donzela-guerreira.

\section{GENDER, SEXUALITY AND NATION: QUEEN GINGA BETWEEN OBLIVION AND INVENTION OF THE WORLD}

\begin{abstract}
In this paper, we analyse the construction of Rainha Ginga, as a character of the two most recently written novels by José Eduardo Agualusa in which this historical figure appears, Teoria Geral do Esquecimento (2012) and $A$ rainha Ginga: e de como os africanos inventaram o mundo (2014). We seek to understand how the literary version of this historical figure can instigate reflections about memory, past and on how national identity relates to gender and sexuality. Our analysis is based on the writings of Inocência Mata (2006, 2014), Mario César Lugarinho (2016) e Helder Thiago Maia (2018) and seeks queer perspectives in which we may understand Ginga as a character.
\end{abstract}

Keywords: Rainha Ginga. José Eduardo Agualusa. Woman warrior.

\footnotetext{
${ }^{1}$ Graduanda em Letras pela USP, Bolsista CNPQ de Iniciação Científica.

2 Doutor em Literatura Comparada (UFF, 2018), realiza estágio de pós-doutoramento, com bolsa da FAPESP no. 2018-19521-4, no Programa de Pós-graduação de Estudos Comparados de Literaturas de Língua Portuguesa da Universidade de São Paulo. E-mail: helderthiagomaia@gmail.com.
} 


\section{Ginga de Angola: traços da construção literária de uma personagem histórica}

A extensa obra de José Eduardo Agualusa é marcada pela reiteração e pela proposição de reflexões sobre alguns temas, como o colonialismo, a memória, o nacionalismo, o olhar crítico sobre Angola, e, ainda, a proposição de aproximações entre os diversos territórios que um dia estiveram sob o domínio do empreendimento colonial português. Além disso, o autor, nascido em Huambo, antiga Nova Lisboa, é conhecido por traçar, em suas obras, inúmeros diálogos com a História.

A obra de Agualusa pode ser identificada com o que Linda Hutcheon (1991) chamou de "metaficção historiográfica", termo utilizado para se referir a obras que questionam a ideia de que só o discurso histórico está submetido a regimes de verdade. Nos termos de Hutcheon (1991, p. 91), "tanto a história quanto a ficção são discursos, construtos humanos, sistemas de significação, e é a partir dessa identidade que as duas obtêm sua principal pretensão à verdade".

Nas produções de Agualusa, portanto, é comum que apareçam personagens históricos, ou, ainda, que personagens de uma obra reapareçam em outra, traçando uma continuidade entre as diferentes descrições desse imaginário agualusiano. Dentre as personagens que se repetem está uma figura histórica de grande proeminência em Angola, a Rainha Ginga ${ }^{3}$. Destacamos ao menos oito textos de Agualusa, sendo sete romances e um conto, em que essa personagem faz ao menos uma aparição: Estação das chuvas (1996); Nação crioula: correspondência secreta de Fradique Mendes (1997); Os pretos não sabem comer lagosta (1999); O ano em que Zumbi tomou o Rio (2002); O vendedor de passados (2004); Milagrário pessoal (2010); Teoria

\footnotetext{
${ }^{3}$ Esta é uma personagem cuja complexidade começa pelo nome. Afinal, ao ser transposto para o português, o nome acabou recebendo diferentes grafias: Ginga, Jinga, Nzinga ou Njinga Mbandi, sendo os dois últimos mais adequados à fonética do quimbundo, língua original do povo de Ndongo (HEYWOOD, 2019). Além disso, a própria personagem adotou diferentes grafias a depender de suas estratégias políticas. Entretanto, como o nome "Rainha Ginga" é mais difundido no Brasil e é o nome adotado com mais recorrência na obra de José Eduardo Agualusa, optamos por privilegiar esta grafia no restante deste artigo.
} 
geral do esquecimento (2012) e A rainha Ginga: e de como os africanos inventaram o mundo(2014).

Entendemos que, mesmo quando a Rainha Ginga é apenas uma aparição, a sua presença nos textos de Agualusa não é banal, uma vez que a personagem produz uma espécie de referência, a partir da qual podemos pensar as perspectivas apresentadas em cada obra, conectando o texto a elementos históricos, culturais e literários vinculados a Angola e a outros países de língua portuguesa. Além disso, a Rainha Ginga, enquanto personagem de caráter histórico e com inúmeras reconstruções literárias, traz, a cada nova menção, toda uma carga de questões de gênero, sexualidade e, ainda, as interseções desses temas com o nacionalismo e mesmo com tradições literárias, como a das donzelas-guerreiras.

Neste artigo, buscaremos pensar a construção da Rainha Ginga nas duas obras mais recentes de José Eduardo Agualusa em que essa personagem está presente: Teoria geral do esquecimento(2012) e A rainha Ginga: e de como os africanos inventaram o mundo(2014)

Para tanto, faremos uma breve introdução à personagem da Rainha Ginga e às principais perspectivas a partir das quais ela é construída na tradição da literatura angolana. Em seguida, apresentaremos dois parâmetros teóricos que embasam nossa análise: (i) as reflexões de Inocência Mata (2006, 2014) acerca de três diferentes abordagens da transposição de elementos históricos para a literatura: o colonial, o anticolonial/nacionalista e o póscolonial; e (ii) as proposições de Helder Thiago Maia (2019) acerca da caracterização da Rainha Ginga como uma donzela-guerreira. Com essa fundamentação teórica, analisaremos a personagem nos romances supracitados e, finalmente, concluiremos o texto de maneira a ressaltar as potencialidades das permanentes reconstruções dessa figura histórica. 


\section{O desafio de queerizar a Rainha Ginga}

Quando falamos de Rainha Ginga, estamos nos referindo, no geral ${ }^{4}$, a Njinga Mbandi, governante do reino de Ndongo e Matamba, território no norte da atual Angola, que viveu entre 1582 e 1663 . Neta, filha e irmã de exgovernantes de seu reino, é uma personagem célebre na história do colonialismo na África Central e em Angola, por causa de sua oposição contundente à ocupação portuguesa. Por conta disso, sua representação histórica tem sido objeto de polêmicas e disputas.

Linda Heywood (2019, p. 7-9) demonstra como o retrato de Ginga feito por seus contemporâneos europeus descrevia alguém de caráter extremamente perverso. Temos, em Istorica Descrizione (2013), do padre Antonio Cavazzi de Monteccucolo, por exemplo, a descrição de alguém que viola todo tipo de padrão aos olhos do Cristianismo, uma vez que Ginga é narrada como uma canibal, assassina de bebês e, ainda, uma mulher que viola as normas de gênero ao vestir-se e viver como homem, autoproclamar-se rei, rejeitar as "virtudes femininas" e manter um harém de pessoas que eram entendidas (colonialmente) como homens, mas que, por ordem dela, viviam como mulheres. O padre Cavazzi cria uma espécie de história-modelo que ressalta o caráter de "salvação das almas" do empreendimento colonial em África. Em toda a sua obra, Cavazzi constrói uma forte oposição entre a Ginga perversa, desumanizada e cruel em sua "natureza africana" e a Ginga "civilizada" após a conversão ao cristianismo. Nesse sentido, sua obra é um forte exemplo de como a perspectiva colonial elaborou uma narrativa de Ginga. Entretanto, seu texto é geralmente lido como um documento histórico e, portanto, como uma fonte mais confiável do que textos de caráter literário. Adiante, com as provocações de Inocência Mata (2006, 2014), buscaremos pensar como a apropriação dessas fontes históricas pode colocar em evidência os interesses escondidos no discurso histórico pretensamente imparcial.

\footnotetext{
${ }^{4}$ A expressão "no geral" ressalva o fato de que a expressão "Rainha Ginga" tornou-se também a alcunha de outras lideranças que resistiram a ocupações coloniais em território africano. Entretanto, no caso de todas as obras analisadas neste artigo, Rainha Ginga designa Njinga Mbandi.
} 
Se, temos, portanto, de um lado, a visão colonial sobre Ginga, podemos identificar, por outro lado, o seu oposto, a visão anticolonial/nacionalista. Como descreve Lugarinho (2016, p. 91), após a Independência de Angola, Ginga foi alçada ao posto de heroína nacional e mãe da Nação angolana. É o que verificamos, por exemplo na leitura do poema $O$ içar da bandeira (1985), de Agostinho Neto, liderança do MPLA e primeiro presidente de Angola, em que Ginga figura ao lado de Ngola Kiluanje em um panteão de heróis da resistência aos portugueses. Nessa visão, a personagem Ginga é "normalizada" para que não apareçam polêmicas como a transgressão do gênero, que poderiam prejudicar a sua reputação de mãe e fundadora da nação.

$\mathrm{Na}$ comparação entre essas duas perspectivas, a colonial e a nacionalista, a questão do gênero é um ponto sensível. Cabe, assim, pensar nas reflexões de Oliveira Mendes (2002, p. 522) sobre o que o autor chama de "identidade narrativa”, ou seja, a ideia de que as identidades não são algo único, homogêneo e estável, mas vão sendo construídas a partir da narrativização dos sujeitos em suas múltiplas experiências e, ainda, em contraste com outros sujeitos. Assim, podemos pensar em como Ginga é narrada de diferentes maneiras e é, ainda, contraposta a diferentes padrões de gênero, nacionalidade e resistência.

Na mesma linha, Lugarinho (2016, p. 91) reflete sobre como essa identidade múltipla de Ginga é construída narrativamente de maneira a associar gênero e identidade nacional. Seu olhar volta-se, então, para a necessidade de perceber como uma análise crítica das construções discursivas da personagem Rainha Ginga pode evidenciar a relação entre os padrões de gênero e os modelos de "homem" e "mulher" angolanos, em larga medida herdados do colonialismo português, alinhados a uma nação relativamente recente e muito marcada por disputas violentas.

É a partir desse panorama e desse confronto entre duas perspectivas que, embora se entendam opostas, legitimam um olhar que necessariamente associa perversidade a transgressões de gênero e sexualidade, que nos propomos a buscar uma leitura queer da personagem Ginga. O desafio de queerizar seria, assim, o de evidenciar como a produção literária conecta-se com posturas políticas. Ao recusar discursos 
hierarquizantes e que negam a possibilidade das transgressões, a postura queer busca fazer da história, da memória, do imaginário cultural e, ainda, da crítica literária, âmbitos de reflexão e de proposição de olhares dissidentes.

Para além do colonial e do anticolonial, o pós-colonial: leituras de Inocência Mata

O desafio de queerizar passa, portanto, pela necessidade de compreender novas possibilidades de abordagem histórica. No texto Representações da rainha Njinga/Nzinga na literatura angolana (2014), a pesquisadora e crítica literária Inocência Mata já havia descrito um panorama semelhante ao traçado por Lugarinho (2016), dividindo as construções da personagem Ginga em duas visões, opostas, uma colonial, que, nas palavras de Mata (2014, p. 23), seria um "discurso de desmerecimento dos Africanos”, e outra anticolonial/nacionalista que descrevia a personagem como “incansavelmente heroica”, nas palavras de Lugarinho (2016, p. 91).

Mas, tanto Lugarinho quanto Mata visualizam também a possibilidade de uma terceira construção, que não se daria nem pela desumanização e nem pela total idealização da personagem. Mata (2006, p. 5280; 2014, p. 23-46), ao analisar as obras de Pepetela, identifica uma "tendência produtiva" na literatura angolana caracterizada pela tensão entre os limites da Ficção e da História. Essa tendência produziria as chamadas "metaficções historiográficas" teorizadas por Linda Hutcheon, que busca, ao produzir o choque entre os discursos históricos e literários, uma reflexão sobre os alinhamentos políticos que orientam todo e qualquer discurso, seja ele “ficcional” ou não.

Um exemplo da construção de uma abordagem pós-colonial em que figura a Rainha Ginga seria a obra A Gloriosa Família - O tempo dos flamengos (1997), de Pepetela. Em sua análise, Mata (2006) entende que romances como esse tratam o passado como um material a ser revisitado e redescoberto pela narrativa ficcional. O discurso histórico, assim, deixaria de ser mera fonte de informações para ser tratado como algo que deve ser investigado, analisado, desdobrado e, muitas vezes, reconstruído.

O grande diferencial, portanto, de obras como o romance de Pepetela, que permitiriam caracterizá-lo como pós-colonial, estaria na sua capacidade de assumir e colocar em evidência as contradições do passado. 
Nesse sentido, a personagem de Ginga não seria alguém cujas possibilidades de representação estariam limitadas a extremos. A construção do olhar sobre a Rainha Ginga, em perspectiva pós-colonial, passaria a entendê-la como uma estrategista dentro de um tabuleiro extremamente complexo e muito mais dinâmico do que a representação estanque de "portugueses versus africanos" consegue abarcar. Passa-se a considerar, assim, a presença dos holandeses na região e, ainda, a multiplicidade que geralmente é homogeneizada sob a ideia de "africanos".

Assim, Mata (2006, 2014), em seus estudos, parece propor a existência de três abordagens que impactam na construção da personagem da Rainha Ginga: a colonial, que adere ao discurso da exploração europeia e desumaniza a população africana; a anticolonial/nacionalista, que passa a entender a resistência à ocupação portuguesa como um mérito que eleva personagens históricos à categoria de heróis nacionais, mas despindo-os de seus possíveis defeitos, em uma construção que também desumaniza pela idealização; e, por fim, a visão pós-colonial, que não necessariamente chancela uma única descrição da personagem, mas busca compreender como cada discurso e imagem de Ginga é feita a partir de uma dentre múltiplas perspectivas que, por sua vez, estão ligadas aos diferentes alinhamentos políticos.

\section{Ginga como donzela-guerreira? As provocações de Helder Thiago Maia}

A proposta de queerizar a personagem da Rainha Ginga ainda tem outra perspectiva, que leva em consideração a importante provocação de autores como Oliveira Mendes (2002) e Lugarinho (2016) sobre a articulação de múltiplos elementos na construção narrativa das identidades. As leituras de Lugarinho (2016) sobre a personagem da Rainha Ginga evidenciam a articulação entre o tema da identidade nacional, do posicionamento em relação ao colonialismo e questões de gênero/sexualidade.

É preciso considerar que a Rainha Ginga é pensada a partir de sua performatividade de gênero e sexualidade dentro da tradição crítica-literária das donzelas-guerreiras. A crítica Walnice Galvão, em sua obra $A$ donzela- 
guerreira: um estudo de gênero (1998), afirma que a Rainha Ginga pode ser entendida dessa forma. Entretanto, a própria autora não analisa nenhuma obra literária em que Ginga aparece como personagem, deixando uma lacuna a ser preenchida no que concerne a essa figura tão importante para a história de Angola e da colonização portuguesa como um todo. Assim, buscaremos entender também se a construção de Ginga pode ser entendida a partir da tradição das donzelas-guerreiras.

Mas, em uma perspectiva queer, é preciso compreender melhor como a produção crítica sobre as donzelas-guerreiras tem sido produzida, ou seja, como se caracteriza esse paradigma. Segundo Helder Thiago Maia (2018), podemos descrever as donzelas-guerreiras, de maneira geral, como personagens que, inicialmente designadas como mulheres no nascimento, assumem uma identidade masculina e vão à guerra, onde são reconhecidos pela bravura. Há exemplos de personagens que morrem na guerra e são "descobertas" como mulheres, afastando, assim, seu romance com outro soldado dos limiares da homossexualidade. Outras personagens sobrevivem à guerra e continuam a viver como homens, jamais transicionando novamente para a identidade feminina.

Em Trangressões canônicas: queerizando as donzelas-guerreiras (2018), Maia, ao revisitar a tradição sobre o tema, apresenta duas críticas. A primeira é o fato de que muitas caracterizações de donzelas-guerreiras são orientadas por um paradigma falocêntrico, pensando essas personagens como sujeitos da "falta", da "inveja do falo", da "negação da identidade", enfim, como "mulheres mutiladas". Trata-se de uma visão que parte de uma perspectiva essencialista e biologizante do gênero, que entende a transição de gênero como uma impossibilidade ontológica, algo que nega as múltiplas expressões do gênero para além do binarismo.

Ainda nesse artigo, Maia constata o alargamento do uso do conceito de donzela-guerreira e a perda de seu potencial crítico, pois o paradigma passou a ser aplicado para enquadrar qualquer personagem que escape dos limites estreitos da feminilidade. Levando em conta o fato de que as normas de gênero impostas às mulheres são muito rígidas e que uma quantidade considerável de personagens femininas está restrita a papeis secundários, percebemos que a ideia de donzela-guerreira alargou-se a ponto de abarcar 
qualquer personagem que pudesse assumir maior protagonismo dentro de uma obra literária.

Buscando recuperar o potencial crítico, portanto, dessas personagens, Maia (2018) propôs o desdobramento do paradigma da donzelaguerreira em quatro: as "mulheres masculinas", que transgridem o ideal de feminilidade sem ir à guerra; as "mulheres guerreiras", paradigma que abarca as mulheres que vão à guerra; as "donzelas-guerreiras", personagens que vão à guerra assumindo uma identidade masculina, mas após a guerra "voltam" à sua identidade feminina; e as "transgeneridades guerreiras", personagens que assumem uma identidade masculina para ir à guerra e, após o conflito, continuam a identificar-se como homens. Essa proposta, como o autor argumenta, busca contrapor-se ao apagamento de diferentes performatividades de gênero, dando visibilidade a personagens que desmantelam a ideia da transição como "impossibilidade".

Assim, o nosso desafio de queerizar o olhar acerca das construções da Rainha Ginga em dois romances de Agualusa levará em consideração, em relação às questões de gênero e sexualidade, como a personagem pode ser associada a um dos quatro paradigmas propostos por Maia (2018). Desse modo, nossa análise ressaltará elementos associados aos conflitos bélicos e às descrições de performatividade de gênero da personagem para compreender se é possível entendê-la a partir dos desdobramentos das donzelas-guerreiras. Inspirando-nos nas reflexões de Mata (2006, 2014), Lugarinho (2016) e Oliveira Mendes (2002), buscaremos entender a articulação desses diferentes elementos da identidade narrativa da Rainha Ginga nos romances de Agualusa.

\section{Queerizando Rainhas Gingas de Agualusa Teoria geral do esquecimento (2012)}

Este é um romance que já apresenta um deslocamento no título, Teoria geral do Esquecimento. A expressão "teoria geral" é frequentemente associada ao discurso científico e a regimes com pretensão de verdade, entretanto, temos um romance, um discurso ficcional. Além disso, o título propõe uma teoria geral do esquecimento, o que coloca em questão o 
problema do passado e da memória. A história aparece, então, como uma construção de narrativa sobre o passado com pretensão de verdade, um discurso que se propõe a combater o esquecimento, mas o que se ressalta no romance é o oposto disso, a percepção de que toda narrativa sobre o passado promove memória e esquecimento ao mesmo tempo.

O passado revisitado pela obra é recente, remete às décadas que conectam a Independência de Angola aos dias atuais. Na obra de Agualusa, é frequente o passeio por diferentes territórios, geralmente conectados pela língua portuguesa. Neste romance de 2012, o autor volta-se para um lugar de grande importância na literatura angolana, a cidade de Luanda, capital de Angola. O romance propõe uma revisitação histórica que passa por três décadas e pelas inúmeras transformações que ocorrem na capital angolana, que é, em larga medida, representativa do cenário político nacional.

O exercício de refletir sobre a memória e o esquecimento se dá por meio de uma observadora privilegiada, isolada no topo de um arranha-céu localizado no Largo do Quinaxixe, em Luanda. A portuguesa Ludovica, que foi morar com a irmã e o cunhado angolano na capital da então colônia, e que, de repente, se vê sozinha em meio a um conflito armado, entre a guerra civil e a instabilidade política. Solitária e ameaçada, ela acaba por erguer uma parede entre o apartamento em que vive e o resto do edifício, passando a sobreviver ali pelas próximas três décadas. Do alto de seu exílio, ainda que ele seja interno à cidade, Ludovica observa as transformações pelas quais Luanda e Angola passam, tentando comparar o que acontece com as lembranças que ela tinha da vida antes de seu isolamento.

Ao mesmo tempo em que acompanhamos a luta invisível e doméstica de Ludovica pela sobrevivência no alto de seu apartamento, seguimos as aventuras de Sabalu, um garoto órfão cuja mãe havia morrido e cujo pai estava desaparecido. O encontro de Ludovica e Sabalu representa também uma nova junção entre passado e presente em que ambos cooperam para a construção de um futuro. É claro que a sua tarefa não é fácil, uma vez que ela depende da superação de inúmeros obstáculos e, ainda, da revisitação crítica daquilo que ficou enterrado, esquecido. 
É em um dos tortuosos caminhos que levam ao encontro das duas personagens que encontramos, neste romance, a menção à Rainha Ginga. Sabalu, que perdera toda a família, sai de sua cidade natal no interior e vai até Luanda, onde estariam seus avós paternos, no Largo do Quinaxixe. Logo ao chegar, ele é interpelado por um personagem curioso:

Entardecia quando a fome o [Sabalu] empurrou até um pequeno bar. Sentou-se, receoso. Pediu uma sopa e uma Coca-cola. Ao sair, um rapaz de rosto inchado, pele muito mal tratada, atirou-o contra a parede:

O meu nome é Baiacu, canuco5. Sou o Rei do Quinaxixe. Apontou para a estátua de uma mulher, no centro do jardim: Aquela é a minha dama. Ela, a Rainha Ginga. Eu, o Rei Gingão. Tens kumbu6? (AGUALUSA, 2002, p. 14751489).

Baiacu, o personagem que fala no trecho anterior, é uma espécie de líder de crianças e jovens que cometem pequenos delitos, como furtos. Ele se arroga o título de "Rei do Quinaxixe", uma referência ao Largo do Quinaxixe, local em que eles se encontram, situado na região central da cidade de Luanda. Esse espaço recebeu, na década de 1950, uma construção associada ao estilo modernista e no qual funcionou o Mercado ${ }^{7}$ até 2008.

Pela sua centralidade, o local tornou-se um símbolo das disputas de poder em Luanda e em toda a Angola. Como apresenta Oliveira Pinto (2014), o poder colonial chamou o espaço de "Largo dos Lusíadas" e, nos arredores, estavam a Avenida dos Restauradores de Angola e Avenida Salvador Correia, referências à expulsão dos holandeses e a retomada de Angola pelos portugueses. Em 2003, porém, já algumas décadas após a independência do país, é erguida no local uma estátua em homenagem a Nzinga Mbandi, a Rainha Ginga. É a essa estátua, que existe no Largo do Quinaxixe, a que Baiacu se refere.

\footnotetext{
${ }^{5}$ Em quimbundo, criança, filho pequeno, caçula.

${ }^{6}$ Dinheiro em quimbundo.

${ }^{7}$ Há muitas formas de grafar o nome: Quinaxixe, Kinaxixe, Kenaxixi, Kinaxixi. Neste artigo, utilizo a grafia utilizada no romance, "Quinaxixe" e a grafia utilizada no nome do mercado, "Kinaxixe".
} 
Os nomes envolvidos remetem a outra menção a Ginga, que aparece no romance O vendedor de passados (2004), de Agualusa. No artigo As Rainhas Gingas de José Eduardo Agualusa: uma análise a partir dos livros Nação Crioula (1997), O ano em que Zumbi tomou o rio (2002) e $O$ vendedor de passados (2004) (2019), discutimos como um personagem chamado de "O ministro" pretere uma descendência familiar Ginga e prefere vincular-se a Salvador Correia de Sá e Benevides por entendê-lo como um herói que expulsou os holandeses de Angola. Ademais, é importante destacar que Ginga e Correia de Sá e Benevides foram inimigos diretos em batalhas, e que a expulsão dos holandeses, à época aliados de Ginga, foi algo que impediu os planos de Ndongo-Matamba não só de fazer frente, mas de colocar um fim na ocupação portuguesa no território.

Podemos concluir, que, em sua obra, Agualusa apresenta múltiplas perspectivas acerca do imaginário que se tem sobre Ginga e Salvador Correia de Sá e Benevides. Se, por um lado, em O vendedor de passados, observamos a coexistência das duas figuras no imaginário angolano, por outro, em Teoria Geral do Esquecimento, com a alusão ao Largo do Quinaxixe e seus entornos, encontramos uma espécie de transição entre duas formas de produção de identidade e unificação em Angola.

Quando as avenidas homenageavam Correia de Sá e os Restauradores, notamos que se pensava em termos de unificação angolana, como se esses representantes do poder colonial português, ao expulsarem os holandeses, tivessem garantido a integralidade do território. Mas, após a Independência, é a resistência à exploração portuguesa que passa a ganhar força com o discurso nacionalista. Podemos observar, portanto, que em conjunto, os romances permitem localizar dentro do panorama "colonial versus anticolonial/nacionalista" a identificação de angolanidade a partir de Correia de Sá e Ginga, respectivamente. Mas, além disso, os romances aludem à coexistência dessas duas visões no contexto atual.

Isso permite, em primeiro lugar, localizar a fala do personagem no século XXI, já vivendo em uma Angola independente há décadas. Isso não significa, entretanto, que as marcas coloniais deixem de aparecer. Baiacu assume uma postura territorialista e, também, nacionalista, ao associar-se à figura de Ginga retratada na estátua, como heroína anticolonial. Percebemos, 
ainda, em seu discurso, como ele delimita Ginga como a referência de sua identidade. Embora ela seja sua "dama”, é do nome da rainha que deriva sua alcunha de rei Gingão.

Quanto à questão da donzela-guerreira, ainda que a menção seja muito breve, podemos notar como há referências ao caráter bélico de Ginga, principalmente com as alusões a Salvador Correia de Sá e Benevides. Quanto ao gênero, há uma reafirmação de sua identidade feminina, pois ela é delimitada como "dama", "Rainha de um Rei". Podemos concluir, portanto, que ela está associada ao paradigma das mulheres-guerreiras proposto por Maia (2018), que descreve as personagens que vão à guerra sem realizar uma transição de gênero. Observamos também como se alinha a construção de Ginga com aquilo que fora apresentado por Lugarinho (2016): a figura "incansavelmente heroica" que é despida de qualquer indício de transgressão de gênero.

No entanto, apesar do discurso do personagem sobre Ginga, o romance em si constrói, como é recorrente na obra de Agualusa, um mosaico de visões sobre a Angola independente. Assim como o autor havia feito em vários de seus outros livros, como Estação das águas (1996) e O vendedor de passados (2004), apenas a título exemplificativo, Agualusa nos apresenta uma Angola marcada por contradições, por posturas autoritárias e pelo desaparecimento de críticos ao governo. Encontramos, assim, uma visão profundamente crítica em relação ao movimento nacionalista e aos seus frutos. E, mais uma vez, Ginga é inserida como um índice que localiza sujeitos, mas dentro de um grande palco onde múltiplas vozes, ações e posicionamentos são expostos.

Por fim, notamos como Ludovica é uma personagem feminina importante, principalmente se comparada com outras personagens femininas de Agualusa, que muitas vezes são definidas a partir do olhar masculino. É o caso, inclusive, da personagem Ângela Lúcia de $\mathrm{O}$ vendedor de passados. Entretanto, temos, em Teoria Geral do Esquecimento, uma mulher que independe do olhar masculino. É curioso que ela passe a maior parte de sua vida, isolada, dentro de sua casa, observando o mundo se transformando ao redor. Seria possível pensá-la como uma imagem da mulher em seu espaço 
privado, doméstico, que precisa superar obstáculos e, finalmente conquistar um lugar também no ambiente público.

\section{A rainha Ginga: e de como os africanos inventaram o mundo (2014)}

Após inúmeras menções curtas, somando-se ao menos seis romances e um conto, a Rainha Ginga torna-se, finalmente, a personagem título de um romance de Agualusa. Podemos notar, a partir desse percurso longitudinal por algumas obras do autor, que essa figura histórica já existia na imaginação literária do autor e vinha sendo sutilmente delineada há anos a partir de um grande mosaico de perspectivas.

Desta vez, a rainha/rei ganha centralidade, mas, ainda assim, não é a sua voz que se faz ouvida no romance. Mais uma vez, Agualusa focaliza o processo de construção da Rainha Ginga, sendo possível pensar que se trata de produzir uma metaficção historiográfica que não diz respeito apenas a momentos históricos, mas concentra-se, principalmente, em revisitar a composição de uma figura histórica. Mais do que desvendar uma verdade histórica, o romance parece investigar como se constrói um discurso em torno dessa figura. O subtítulo já evidencia o problema da "invenção" e coloca uma questão para nós que lemos o romance, como os africanos teriam inventado o mundo? Ou melhor, como propõe Maia (2019), como os africanos estariam a inventar o mundo?

Dessa vez, somos apresentados a um narrador, o padre Francisco José da Santa Cruz, que nascera em Olinda e atravessara o Atlântico para trabalhar na missão evangelizadora, grande aliada e fiadora das atrocidades coloniais. Mais uma vez, mesmo voltando ao século XVII, Agualusa reforça as conexões entre Brasil e Angola, como já havia feito em outras de suas obras, como Nação crioula e $O$ ano em que Zumbi tomou o Rio (SILVA, MAIA, 2019). Além disso, nos coloca, como fizera em Nação crioula, diante de um representante do poderio colonial que, no decorrer de sua aventura em África, terá suas crenças e sua lealdade postas à prova.

Ginga é uma figura impulsionadora da transformação pela qual o padre narrador passa, afastando-se cada vez mais de sua fé cristã e de seu 
compromisso com o colonialismo para, por meio da sua autocompreensão como súdito da Rainha Ginga, africanizar-se, como analisa Maia (2019). No mesmo sentido, o crítico aponta um paralelo entre a personagem do padre Santa Cruz com o padre Antonio Cavazzi, citado ao final do livro por Agualusa dentre as fontes de pesquisa histórica para a construção do romance. Podemos estabelecer, assim, uma subversão dos escritos de Cavazzi, Istorica descrizione. Se, na visão do capuchinho, Ginga passa de "bárbara" a "católica civilizada", neste romance, o padre Santa Cruz vai de missionário católico a súdito do reino do Ndongo, por causa de Ginga, algo que, em uma perspectiva colonial, representaria a passagem do "civilizado" para o "bárbaro".

O movimento de inversão do romance, como bem descreve Maia (2019), modifica também a direção da atribuição da barbaridade. Ginga tornou-se célebre na historiografia do mundo colonial por, dentre outros motivos, ser retratada como "uma canibal sanguinária que não hesitava em assassinar bebês e trucidar seus inimigos" (HEYWOOD, 2019, p. 7). O relato histórico-literário do Pe. Santa Cruz coloca essa descrição em xeque, por exemplo quando este afirma que "nunca os vi praticar sacrifícios humanos e muito menos devorar carne de gente" (AGUALUSA, 2015, p. 83).

Maia (2019) comenta a questão do canibalismo, argumentando que a atribuição de tal comportamento pelos portugueses a povos que seriam "dominados" era comum e acontecera também com povos indígenas brasileiros. Esta era uma tentativa de justificar a colonização como uma missão divina. A isso, o padre Santa Cruz também oferece uma resposta, evidenciando a hipocrisia e a barbaridade dos portugueses logo no início do romance:

Tantos anos decorridos, olhando sobre os meus débeis ombros para o alvoroço do passado, sei não serem tais práticas [referindo-se às testemunhadas no Ndongo] mais diabólicas do que tantas outras de que eu mesmo fui testemunha no seio da Igreja Católica. Violências, injustiças, infindáveis iniquidades, que a mim se me afiguram ainda mais torpes do que as cometidas pelos ímpios, pois se aqueles ignoram Deus, os cristãos erram em nome Dele (AGUALUSA, 2015, p. 11-12).

As tropas portuguesas degolaram nesse dia muitos milhares de guerreiros ambundos. Como testemunho da 
façanha, arrancaram os narizes aos cadáveres, levando para Luanda a infame carga (AGUALUSA, 2015, p. 13-14).

Maia (2019) também nota a atribuição de barbaridade ao português em relação ao quimbundo, como se vê na passagem acima transcrita. $\mathrm{O}$ autor ainda aponta para uma perspectiva decolonial no romance de 2015. Na mesma linha, poderíamos considerar, baseando-nos nas lições de Inocência Mata (2006), que se delineia um olhar pós-colonial, uma vez que as visões coloniais são apresentadas para serem questionadas, propondo-se, assim, uma revisitação da produção dos discursos históricos sobre Ginga, o reino do Ndongo-Matamba e a resistência à colonização portuguesa.

Conforme nota Maia (2019), podemos observar como essas revisitações históricas superam a mera oposição africanos versus europeus, para revelar uma intrínseca rede de relações e estratégias que envolviam múltiplos posicionamentos africanos e inúmeros interesses europeus, com destaque para os de Portugal e Holanda. Podemos afirmar, portanto, que o desenvolvimento da personagem de Ginga também resultou em uma complexificação do olhar que se constrói ao redor dela.

Isso também vale para a questão das transgressões de gênero, que finalmente são colocadas em debate. Heywood (2019, p. 7) registrou que “acusaram-na [Ginga] de desafiar as normas do gênero ao vestir-se como homem, liderar exércitos, ostentar haréns de homens e mulheres e rejeitar as virtudes femininas de criar e cuidar dos filhos". Entendemos que seria, desse ponto de vista, bastante questionável se a obra literária encobrisse tais aspectos, muito embora isso tenha sido feito em outros textos sob a justificativa de criar, como dissemos, uma "mãe" da Nação "incansavelmente heroica" (LUGARINHO, 2016).

É nesse aspecto, aliás, que talvez possamos observar mais a demarcação do foco narrativo, atribuindo-se a voz a um padre do século XVII. Isso porque, apesar de deixar-se africanizar, Santa Cruz demonstra grande dificuldade em compreender a possibilidade das transições de gênero. Algo, aliás, que não era apenas a regra alguns séculos atrás, mas que também enfrenta grande resistência nos dias atuais. Dessa maneira, para analisar a questão, precisaremos atentar-nos a pequenos indícios no texto que nos 
levam a visualizar como Ginga se apresenta e é compreendida pelas pessoas em seu entorno:

Ginga discutia em alta voz com o irmão, como se com ele partilhasse a mesma vigorosa condição de macho e de potentado. Já na altura não admitia ser tratada como fêmea. E era ali tão homem que, com efeito, ninguém a tomava por mulher (AGUALUSA, 2015, p. 12-13).

A Ginga, agora rainha Ginga, ou melhor, rei Ginga, porque assim exigia ser tratada, queria ver-me (AGUALUSA, 2015, p. 49).

Encontrei-a vestida à maneira de um homem, como rei que se arvorava ser, tão macho quanto os demais, ou mesmo mais, e armada de arco e flechas. [...]

Ela - o rei - gritou algumas ordens em quimbundo, que não compreendi, e logo uma série de jagas saíram apressados (AGUALUSA, 2015, p. 60).

Observamos uma incongruência entre o pronome utilizado pelo narrador para referir-se à personagem e a maneira como Ginga se apresenta $\mathrm{e}$ como é percebida pelas pessoas. Ao vermos que a personagem se apresenta como "rei", podemos verificar que sua identidade masculina extrapola o conceito bélico, e, por esse motivo, concordarmos com Maia (2019) também no que tange à associação da personagem ao paradigma das "transgeneridades guerreiras". Compreendemos que, ao extrapolar a apresentação masculina para além dos momentos de guerra, Ginga deixa de enquadrar-se dentro dos parâmetros da "donzela-guerreira". Notamos, entretanto, que é importante ressaltar que nossa consideração diz respeito à personagem e não pretende, em momento algum, tecer algum discurso de verdade acerca da figura histórica.

Destacamos, ainda, que as "transgressões" de Ginga não se limitam à sua própria identidade de gênero, mas abarcam também as suas relações com suas amantes. O harém, aliás, não é uma novidade na obra de Agualusa, pois ele já havia sido retratado em Milagrário pessoal (2010). O harém é composto, assim, por um conjunto de pessoas designadas no nascimento como homens, que vivem, a mando de Ginga, como mulheres: 
Dei com uma mulher, postada à ombreira do cercado, imóvel e alheia. Aproximei-me. A Lua brilhava na noite, como um redondo rasgão aberto numa tenda de couro, iluminada por dentro. Descia dela uma luz macia, esparsa, que mal deixava distinguir as formas. Só quando estava a poucos passos percebi o engano. A mulher era um homem. Julguei, na confusão do primeiro instante, haver tropeçado num nganga dia quimbanda, ou sacerdote do sacrifício. A singular personagem, porém, não trazia a longa e desarrumada gadelha que é apanágio daquela classe de bruxos. Pelo contrário, ostentava uma alta, habilidosa e perfumada cabeleira de mulher. No rosto, muito bem raspado, de traços perfeitos, havia um vago sorriso de troça. Cumprimentei-o em quimbundo, tentando esconder o susto de o encontrar ali: um homem vestido de mulher, guardando aves mágicas. O meu pobre quimbundo fê-lo abrir o sorriso um pouco mais. Nesse tempo eu ainda não falava com fluência a língua do país, tropeçando a cada palavra, mas já era capaz de manter uma pequena conversa. O homem disse chamar-se Samba N'Zila e ser uma das esposas do rei. Tive um outro momento de perturbação, que logo ele compreendeu, pois, voltando a sorrir, acrescentou:

- O rei, a Ginga.

Domingos Vaz havia-me dito que a rainha mantinha um serralho, à maneira dos sultões turcos, colecionando fidalgos da sua corte, aos quais obrigava a trajar como se fossem fêmeas. Na altura não lhe dei crédito. Samba N'Zila confirmou tudo o que o tandala me confidenciara (AGUALUSA, 2015, p. 84-85).

O longo trecho acima não apenas descreve o harém, como permite ratificar a associação de Ginga como uma personagem associada às "transgeneridades guerreiras" e a comportamentos desviantes da norma cristã e colonial de gênero e sexualidade. Reiteramos, ainda, a caracterização da perspectiva do romance como pós-colonial, pois não busca "aparar" a personagem e despi-la de possíveis polêmicas. Pelo contrário, Ginga é alguém que encanta o narrador, mas que, ao mesmo tempo, é descrita em suas facetas bélicas, com sua ambição e seus desejos. 


\section{Rainha Ginga: ainda um desafio}

Neste artigo, analisamos os dois romances mais recentes de Agualusa em que a Rainha Ginga figura como personagem. Podemos observar que as aparições da personagem são muito distintas. Se, em Teoria Geral do Esquecimento(2012), há apenas uma menção à figura, em A Rainha Ginga: e de como os africanos inventaram o mundo (2015), ela torna-se a personagem título e o tema central da narrativa. Entretanto, em ambos os romances, é possível notar como o processo de trazer uma figura histórica para uma ficção, ou melhor, uma "metaficção historiográfica", nos termos de Hutcheon (1988), pode produzir um olhar que alinha-se ora com a perspectiva colonial, ora com a anticolonial/nacionalista, ou ainda, com uma abordagem póscolonial, como propõe Mata (2006, 2014).

Retomando as discussões de Silva e Maia (2019), consideramos que a presença da Rainha Ginga nas obras de Agualusa apresentam uma continuidade e exploram questões vinculadas ao imaginário histórico de Angola. Notamos, em relação aos romances analisados, especificamente, que Agualusa busca apresentar uma multiplicidade de perspectivas e, ainda, que o autor não esconde as contradições da memória e do passado, alinhando-se, assim a uma perspectiva pós-colonial.

Notamos como a construção literária de Ginga articula questões de identidade nacional, de gênero e de sexualidade. No contraste entre as duas obras de Agualusa, percebemos que, em Teoria Geral do Esquecimento, podemos pensar a personagem como uma mulher-guerreira, por seu caráter bélico, mas sem transicionar de gênero, enquanto em $A$ Rainha Ginga: e de como os africanos inventaram o mundo, a personagem ganha uma descrição muito mais detalhada e pode ser associada ao paradigma das transgeneridades guerreiras, pois se trata de uma personagem que vive uma identidade masculina para além do contexto bélico. Acreditamos, assim, que analisar os textos literários sobre a Ginga permitiu trazer uma perspectiva queer sobre a tradição das donzelas-guerreiras, como propõe Maia (2019), de forma a resistir ao apagamento de personagens que transicionam entre os binarismos de gênero. 
Por fim, destacamos a complexidade e o caráter multifacetado da personagem, que a cada nova aparição no universo literário traz consigo um grande número de questões e um convite a reflexões sobre gênero, sexualidade, nação, história, memória e identidade. Nesse sentido, não é possível caracterizar Ginga de maneira estanque e necessariamente como uma donzela-guerreira. No entanto, podemos dizer que as narrativas, mesmo as coloniais, a inscrevem dentro das lutas contra o colonialismo português, traço que aparece também nas narrativas pós-coloniais, como nos dois romances de Agualusa aqui analisados.

\section{Referências}

AGOSTINHO NETO, Antônio. O içar da bandeira. In: Sagrada esperança. São Paulo: Ática, 1985.

AGUALUSA, José Eduardo. A Rainha Ginga: e de como os africanos inventaram o mundo. Rio de Janeiro: Foz, 2015.

AGUALUSA, José Eduardo. Milagrário pessoal. Rio de Janeiro: Língua Geral, 2010.

AGUALUSA, José Eduardo. O Vendedor de Passados. Rio de Janeiro: Gryphus, 2004.

AGUALUSA, José Eduardo. Teoria geral do esquecimento. Rio de Janeiro: Foz. Edição Kindle, 2012.

CADORNEGA, António de Oliveira. História geral das guerras angolanas. 3 tomos. Lisboa: Agência-Geral do Ultramar, 1972.

CAVAZZI DE MONTECUCCOLO, Giovanni Antonio. Njinga, Rainha de Angola. Lisboa: Escolar Editora, 2013.

GALVÃO, Walnice. A donzela-guerreira: um estudo de gênero. São Paulo: Senac, 1998.

GAMA, Luiz. Trovas burlescas e escritos em prosa. Org. Fernando Góes. São Paulo: Cultura, 1944.

HALL, Stuart. A identidade cultural na pós-modernidade. Tradução de Tomaz Tadeu da Silva e Guacira Lopes Louro. Rio de Janeiro: DP\&A, 2006. 
GÊNERO, SEXUALIDADE E NAÇÂO: A RAINHA GINGA ENTRE 0 ESQUECIMENTO E A INVENÇĀO DO MUNDO

HEYWOOD, Linda. Jinga de Angola: A Rainha guerreira da África. São Paulo: Todavia, 2019.

HUTCHEON, Linda. Poética do pós-modernismo: história, teoria, ficção. Trad. Ricardo Cruz. Rio de Janeiro: Imago, 1988.

LUGARINHO, Mário. A apoteose da Rainha Ginga: gênero e nação em Angola. In: Cerrados, Brasília, v. 25, n. 41, p. 88-96, 2016.

MAIA, Helder Thiago. Trangressões canônicas: Queerizando as donzelasguerreiras. In: Cadernos de Literatura Comparada (Univ. do Porto), n. 39, p. 91$108,2018$.

MAIA, Helder Thiago. Notas sobre donzelas-guerreiras, gênero e sexualidade em A Rainha Ginga de José Eduardo Agualusa. Revista Mulemba, v.11, n. 20, p. 74-96, 2019.

MAIA, Helder Thiago. A ginga da Rainha: apoteose da Rainha Ginga no carnaval carioca. Moderna Sprak, v. 113, n. 1, p. 129-163, 2019a.

MAIA, Helder Thiago. Entra na roda e ginga: imaginário literário brasileiro sobre a Rainha Ginga. No prelo, 2019b.

MAIA, Helder Thiago. Cangoma me chamou: Outras fontes para a Rainha Ginga na literatura brasileira. 2020. No prelo.

MAIA, Helder Thiago; LUGARINHO, Mário. Uma rainha em três continentes. gênero e sexualidade em torno de Nzinga Mbandi. 2020a. No prelo.

MATA, Inocência. Laços de Memória \& Outros Ensaios Sobre Literatura Angolana. Luanda: União dos Escritores Angolanos, 2006.

MATA, Inocência. Representações da rainha Njinga/Nzinga na literatura angolana. In: A Rainha Nzinga Mbandi: História, Memória e Mito. MATA, Inocência (Org.). Lisboa: Edições Colibri, 2014.

OLIVEIRA MENDES, José Manuel. O desafio das identidades. In: SANTOS, B. S. (Org.). A globalização e as ciências sociais. São Paulo: Cortez, 2002.

OLIVEIRA PINTO, Alberto. Representações culturais da Rainha Njinga Mbandi (c.1582-1663) no discurso colonial e no discurso nacionalista angolano. In: Tavares, Célia Cristina da Silva; Cruz, Maria Leonor García da, coords. Estudos Imagética. Rio de Janeiro: UERJ/CH-FLUL, 2014.

SILVA, Mariana Alves; MAIA, Helder Thiago. As Rainhas Gingas de José Agualusa: Uma análise a partir dos livros Nação Crioula (1997), O Ano em que 
Zumbi Tomou o Rio (2002) e O Vendedor de Passados (2004). In: Revista Crioula (USP), v. 1, p. 173-182, 2019.

Recebido em 5 de Agosto de 2020.

Aceito em 30 de outubro de 2020. 